\title{
Reflection on the Construction of Center of Teaching and Learning Development in China University
}

\author{
Yong $\mathbf{L i}^{1,2}$ \\ ${ }^{1}$ College of Education, South-Central University for Nationalities, Wuhan, China \\ ${ }^{2}$ Center for Faculty Development, South-Central University for Nationalities, Wuhan, China \\ Email: historytown@126.com
}

How to cite this paper: Li, Y. (2017). Reflection on the Construction of Center of Teaching and Learning Development in China University. Creative Education, 8, 13021314.

https://doi.org/10.4236/ce.2017.88092

Received: June 15, 2017

Accepted: July 15, 2017

Published: July 18, 2017

Copyright $\odot 2017$ by author and Scientific Research Publishing Inc. This work is licensed under the Creative Commons Attribution International License (CC BY 4.0).

http://creativecommons.org/licenses/by/4.0/

\begin{abstract}
Since 2011, China's universities have established the Center of Teaching and Learning Development (CTLD), which has become a new measure to drive the teaching reform in colleges and universities, promoting the development of teachers' teaching and learning, and improving the quality of personnel training. At present, the research on CTLD in universities has become a hot issue among the researches of higher education in China, but some basic confused questions on it are still unclear. CTLD is an exotic concept derived from the United States; therefore, in the process of localization or sinicization, we need to answer some major questions: What is the center? Why should we construct the center? How to construct it? What should be constructed? This paper maintains that CTLD in Chinese universities and colleges is a policy-driven, exogenous center construction mode which is different from the endogenous center mode of European and American universities. As a service academic entity, CTLD is designed to respond to the mission of the teacher, the change of the social environment and the needs of the teacher's development. The construction method needs to follow the supportive, holistic, serviceable and differentiated principles, carrying out effective work under the progressive ways of foundation, expansion and characteristics to achieve the localization of the central construction, thus promoting the development of the Center so as to eventually shoulder its due mission. This paper will elaborate the China's CTLD from five aspects, including its status quo of researches, organization orientation, origin of founding, and construction principles.
\end{abstract}

\section{Keywords}

Center of Teaching and Learning Development, Service Academic Entity, Construction Principle, Development Content 


\section{Introduction}

Since 2011, China colleges and universities have established Center of Teaching and Learning Development (hereinafter referred as "CTLD" or "the Center") successively, which has become a new measure to drive the teaching reform in colleges and universities, promoting the development of teachers' teaching and learning, and improving the quality of personnel training. At present, the research on CTLD in universities has become a hot issue among higher education researches, but some basic problems about CTLD in academic circles haven't been made clear yet. The CTLD is an exotic concept derived from the United States; therefore, in the process of localization, we need to answer some major questions: What is the center? Why should we construct the center? How to construct it? What should be constructed? Clarifying these four problems mentioned above will help us promote the future development of the Center.

\section{The Research on Status Quo of Center of Teaching and Learning Development}

As we all know, recently emerging in the field of higher education, CTLD is exotic. Its prototype can be traced back to 1962, the University of Michigan established Center for Research of Learning and Teaching (CRLT), the Center is regarded as a mode by other universities because of its significant role in raising teaching quality. Since then, Harvard University, Stanford University and other colleges and universities in 1970s have also established similar institutions in succession. Later, this development trend of building center affected Canadian, British, Australia, Japan and other countries.

Since the University of Michigan had set up a center, there are about 1000 Teaching and Learning Centers in universities and colleges throughout America by now. In the book Advancing the Culture of Teaching on Campus. How a Teaching Center Can Make a Difference, written by Constance Cook, Matthew Kaplan (Cook \& Kaplan, 2011), it introduces the initiatives and fruits achieved by teachers' development in Center for Research in Learning and Teaching in the University of Michigan. In 2011, the Chinese version of this book translated by Chen Jin and Zheng Yaoli began to issue, I Personally hold that this is the earliest theory and practice monograph of CTLD translated by China scholars. Later, Mary Deane Sorcinelli, Ann E. Austin Edited Creating the Future of Faculty Development. Learning from the Past, Understanding the Present (Sorcinellir, Austin, Eddy, \& Beach, 2005) and other similar works began to be translated, although the English version is earlier than Constance Cook's translation. However, the current kind of teacher teaching academic translation is also slightly inadequate overall and relatively backward in updating.

The Center, still a new thing at home, is still in preliminary stage. In 2006, the Chinese Ministry of Education selected a delegation including 24 members to participate in a two-week forum in the University of Michigan in May, its theme is "Michigan-China University Leadership Forum". Konstantins Cook, a director of the Center for Research in Teaching and Learning in University of Michi- 
gan was specifically in charge of the forum. The forum not only raised the reputation of the Michigan University in China, more importantly, the China's domestic university leaders were inspired by the University of Michigan and began to set up similar Centers spontaneously.

On July $1^{\text {st }}$, 2011, the Ministry of Education and Ministry of Finance put forward Ideas on the implementation of undergraduate teaching quality and teaching reform project during the 12th Five-year plan period, and led colleges and universities to establish CTLD with characteristics of their universities. On July 12, 2012, Ministry of Education of Higher Education promulgated the on notice ushering in national demonstration Center of Teaching and Learning Development, and announced that the first 30 national-level demonstration the Center of Teaching and Learning Development in October. Since then, the provinces have also started the construction of the provincial demonstration Center.

In this context, construction practice and theoretical research on the domestic Centers began to flourish, and researchers, college teachers, college managers all have joined the work. At present, domestic scholars mainly focus on the four aspects of CTLD.

First, Centers in European and American universities have been introduced. America is the founding country of CTLD and one higher education superpower in the world, its experience of running CTLD has attracted China scholars, and many integrity works appear (Xu Yanyu, 2009; Wu Zhenli, 2010; Qin Guanying, 2016), as the Center in the University of Michigan is outshine other centers, China scholars pay more attention to it (Zhang Lili, 2006; Li Yu, 2013; Li Yong, 2015; Zhang Yanping, 2015; Guo Dehong \& Xu Yanyu, 2011; Qu Liaojian, 2016; Ji Yan \& Wang Xia, 2017). Except the United States, scholars also pay close attention to Britain, Australia, Canada and many other world's leading university centers (Huang Ruiyan, 2012; Zhang Baohui, 2013; Cui Chengcheng, 2016; Yang Yingying, 2016; Lu Daokun, 2017; Ma Guihua, 2017). From the perspective of comparative education, the above researches have provided valuable preliminary design experience for domestic CTLD.

As a new organization in China colleges and universities, the target setting and the attribute of the Center have brought widespread attention. (Wang Xia \& Cui Jun, 2013; Fan Xiying, 2013; Chen Li \& Zhao Gang, 2013; Wei Lina, 2016; Chen Dayun, 2016), as the Analects of Confucius goes, "if the name is not right, then the speech will not be in order, and if the speech is not in order, then nothing will be accomplished". At present, academic circle has reached a basic consensus on academic attribute of service, but they hold different opinions on the research and the administrative as well as other aspects.

Third, the domestic scholars also reflected construction of Center. With the successful practice of CTLD depending on the guiding ideology and the strategic arrangement transformation, reviewing the construction of the Center in domestic university, there are many main problems: the Center localization characteristics are not clear; The Center lacks of attraction to teachers; the supervision mechanism of working effect is not perfect. 
To solve these problems, scholars reflect the Center's construction from different aspects and put forward related suggestions including a clearer positioning and more attractive Center, more sound reform mechanism of operation on the current situation of the reflection (Wang Zhongxiang, 2012; Xiong Jingjing, 2013; Li Honghui, 2013; Shen Guipeng, 2014; Li Yong, 2015; Liu Liangliang, 2015; Ding Xuanning, 2016; Xing Qi, 2017).

Fourth, the domestic scholars summarized the work of the Center. After several years of development, the domestic CTLD developed from the start-up phase into the promotion period. In the process of development, the Center managers or participants consciously began to summarize the history of Center construction and experience, such as CTLD in Xi'an Jiaotong University (Ma Zhien, 2012), Shanghai Jiao Tong University (Gao Jie, 2013), Zhejiang University (Liu Lanlan, 2013), Wuhan University (Chen Chen, 2013), Capital University of Economics and Business (Wu Dongmei, Shen Minrong, 2014) Nanjing University (Wang Shouren, Shi Linmiao, 2016) and CTLD in other colleges and universities.

In general, at present, the development model and system design of the domestic Center are still in the initial stage. Unlike the endogenous origin of the European and American universities, China's universities are mainly exogenous center construction mode under the policy-oriented mode. In this process, this exotic needs a localization or the process of localization, looking at the domestic scholars of the study, there are some weak links have not been taken seriously. For example, although they have recognized the attributes of the central service, but the positioning and role of the understanding is not clear; in the specific development content, the Ministry of Education must discuss how to readjust the applicability on the six basic functions of the Center in the future construction. And the Center not only needs to focus on how teachers teach, but also should pay more attention to how teachers assist students to learn, only if the significance of the idea is emphasized can the future project system of the Center be completed.

\section{What Is CTLD?}

Since the Ministry of Education launched the National Demonstration of CTLD in 2012. It as a new organization in domestic colleges and universities, has emerged, been reconstructed and structured. The extensive construction of the Center provides a compensatory possibility for strengthening and supporting the "teaching and learning" at the organizational level. Through a period of theoretical research and practical exploration, the Center may maintain an independent system, or anchor to other institutions, but their functions as a service academic entity have been increasingly recognized by public.

This paper holds that CTLD is a university institution with the main development content of "teaching and learning", taking individuals (teachers and students) development and organizations development as the fundamental way to enhance teachers' teaching, promote students' study and advance teaching organization. The particularity of CTLD in universities lies in the role of service-oriented academic entity. As a new organization, CTLD has three attributes 
or three roles, namely, the basic service attribute showing as the supporter role; the inner academic attribute manifesting as the researcher role; external entity attribute playing a role of executors.

First, the top priority responsibility of CTLD lies in providing service and support, with the former as its basic feature of the internal support system of the Center in colleges and universities, serving the development of higher education institutions, and its ultimate value of its existence can always be reflected on teachers and students. All the work around the "teaching and learning" must take this goal as a fundamental measure standard, which is also a right direction for the Center to enhance their own development. In order to provide more efficient, more quality services, as the Center playing the role of supporter, it should have strong rational supporting and rich human and material resources. Thus, this requires the Center to play two other roles, the researchers and the executors.

Second, academic study is internal motivation of CTLD. From the purpose of view, the academic level of CTLD determines professional level of guiding teachers, and how the degree of specialization directly affects the quality and effectiveness of services for teachers and students. Thus it can be seen that the academic nature of the Center is an intellectual security for satisfying demands of its clients, but it's also the main symbol to difference other service agencies in universities internal systems. To highlight its academic, it is necessary to adhere to research-oriented strategies, relying on multidisciplinary teachers from Pedagogy, Psychology, Management, and taking the strategies into practice in curriculum and activities, it's the only choice that works.

Third, since it is a substantive organization, accompanying administration is inevitable. But the administration is only the external form of the Center, under the organizational structures of universities; the Center should be the flexible executors. Any system's efficient operation can't be separated from information exchange and cooperation. In order to better the operation of colleges and universities, the Center can play its organizational advantages and finally provide resources for healthy development of colleges and universities by integrating high-quality resources, optimizing the teaching environment, deepening departmental cooperation and setting up communication bridges among colleges and universities. However, the central administrative trait among teacher-student relationships should be diluted so as to differentiate itself from "governing" organizations and teaching and learning finally become "serving" organizations for teaching and learning.

As an academic service entity of CTLD, service attribute is a guide prerequisite and foundation for its academic nature and entity attribute. The three attributes, supplementing and facilitating to one another, with its derivative three roles together jointly constitute a solid triangle. By doing so, its core values and aims can be fully demonstrated by setting up a people-oriented, flexible ser-vice organizations to escort for the development of teaching and learning in universities and re-verse the penetration of enterprise management model in the development of teaching and learning. 
The reasons why put CTLD in the position of service academic entity, mainly based on the development trend of higher education in the world, the modernization of China's higher education governance, and needs of catering to the transformation of traditional teachers training system to the teachers teaching and learning development. Since the 1980s, the world's higher education has entered an era of taking quality as the core, showing a focus on the assessment of colleges and universities, putting close attention to undergraduate teaching reform movement. With the higher education becoming universal, it not only has brought the number of colleges and universities to rise, but also has formed the differences of individuals. Under the ways of changing, the teaching and learning subject, no matter it's teacher's teaching or student's learning, both need to get external support, help and study. Response to the criticism of the scale of university expansion and the decline in teaching quality, the European and American universities change internal organizations, which just has proved this point. Therefore, the world's first-class colleges and universities have established CTLD to promote the professional development of teachers so as to enhance the quality of students' learning. Teaching and learning development organizations with the purposes of forming a good teaching and learning culture are on the right side of trend. This kind of teaching support system, which is based on the university's own system, aims to enhance the teaching and learning and show its internal teaching support system that has become the most popular way to improve the quality of teaching and learning in universities.

\section{Why Establish CTLD?}

CTLD is derived from a teacher development resolution of the American Academic Committee, which is established by universities based on the requirements of the education authorities or the future development goals of universities. As an organic part of the teaching quality assurance system in colleges and universities, the Center have more than 50 years history in Europe and the United States, and its development is relatively mature.

\subsection{To Create CTLD Is in Response to the Mission China Entrust to Teachers}

In 2014, exactly on the 30th Teacher's Day, Xi Jinping, General Secretary of the CPC Central Committee, shared his ideas in the forum with teachers and students representatives of Beijing Normal University. He said, "three inches chalk and three feet of stage can decide a country's destiny, which stresses the status and importance of teachers; an earnest heart and a life candle can shape our national spirit, which refers to the teacher's responsibility and mission" (Xi, 2014). On the eve of the Teacher's Day of 2015, Xi Jinping also encouraged the teachers, "Being committed to be pioneers to education reform and education poverty relief as well as leaders to student's growth", which put forward the requirements for the majority of teachers, meanwhile, injected the power and pointed out the direction (Xi, 2015). During his visit to Beijing Bayi School on September 9th, 
2016, Xi said, "the majority of teachers need to be the guides to shape and refine student's personality, to impart knowledge, to cultivate students' innovative thought and to inspire students to dedicate to their country".

In recent years, the state has issued many documents about the construction guidance for teachers, such as State Council issued a document opinions on strengthening the construction of teaching staffs in 2012, that year, Ministry of Education and other ministries issued opinions on strengthening the construction of young teachers of higher education, Ministry of Education in 2014 issued Opinions on establishing and improving a long-term mechanism for the construction of teachers' Ethics in Colleges and Universities. The above remarks and related documents show that the state attached more importance to the cause of higher education, especially to young teachers. Therefore, in the process of popularization of higher education in China, we must pay attention to the development of teachers in colleges and universities, especially the teachers' teaching and learning development, in respond to the mission of teachers in the new era.

\subsection{To Establish CTLD Is in Respond to the Social Environment Changes in China}

Change is the eternal companion of educators, establishing CTLD dues to the changes in the social environment in China, for example, in the context of "encouraging people to start businesses and make innovations", teachers need to spread the innovative fire, schools should take stimulating creativity and tapping innovation potential as development direction of educational reform. In the new era, the relevant educational environment in the development of colleges and universities is also changing. First, with the development of society, since the medieval universities had established, the functions of universities have been constantly evolving and becoming more and more abundant, expands from the initial teaching to four main functions: teaching and learning, scientific research, social service, cultural heritage. Second, in the new period, China's higher education has stepped into mass education from the elite education, many new problems also comes on its heels, taking "put more efforts on researches while make light of teaching" for example, this trend has become increasingly prominent, which isn't conducive to personnel training. Thirdly, the main teaching models change from the traditional "teaching" to "learning", that is, teacher-based (teaching) to student-based (learning). Fourth, educational technology innovation brings opportunities and challenges. For example, in the Internet age, online education not only moves the traditional classes to the web, more importantly, its open resources liberate people's learning, and turn people passively accepted learning from the school to take the initiative to learn. If learning becomes an autonomous action, the roles of teachers and education institutions need be reoriented.

\subsection{To Create CTLD Is in Respond to the Needs of Teachers' Development in China}

With our higher education turning from denotative development to connotative 
development, the teachers' development has become an important part of the connotation development of universities, the key link to determine the quality of higher education, and an effective way to enhance the inner strength of University soft power. However, there are still many problems in the teaching and learning development for teachers. For example, the training mechanism is lagging behind, teachers suffer from job burnout and young teachers encounter "survival predicament". Among them, to enhance the teaching capacity of young teachers is an urgent realistic demand. In recent years, with the change of teachers' structure, young teachers have become the main body of university staff. The latest statistics of the Ministry of Education show that the number of young teachers under the age of 35 is 646,000 , accounting for $45 \%$; Teachers under the age of 40 is 884,000 , accounting for $62 \%$. Therefore, to enhance the teaching skills of young teachers, not only is the fundamental guarantee of improving the quality of personnel training, but also is a self-development direction for young teachers (Fan, 2014).

With communities attach more importance to enhance the quality of higher education; CTLD has also attracted more and more attention. In July, 2016, the Ministry of Education (ME) issued the Guiding opinions of the Ministry of Education on deepening the reform of teaching and learning in Colleges and Universities affiliated to central departments, which put forward "teacher training system have to achieve the goals of institutionalization, specialization, networking by 2020 ", "to universally establish CTLD, to carry out teacher training, teaching and consulting services, teaching reform research, teaching quality assessment, to build quality teaching resources, to improve Teachers' teaching abilities and professional levels, to play the demonstration, radiation and leading role of the national demonstration the Center (ME, 2016)". It can be seen that the support of the national policies for the development of the Center will be a long-term supporting.

\section{How to Construct CTLD?}

In the process of fully deepening the comprehensive reform of higher education, how to plan and design CTLD is the urgent problem to construe the Center.

\subsection{Adhere to the Principle of Support, Make Target Positioning Clear}

The Center as a service organization, now is arriving a general consensus. CTLD in Shanghai Jiao Tong University proposed to carry out systematic research and quality diagnosis for teachers teaching and students learning, to build communication platform and provide personalized help for enhancing teachers' teaching ability (SJTU, 2015). As a service organization, the Center must first figure out the key objects of "support" work, namely teachers, students, institutions and colleges themselves. This determines that the work of the center should not be independent, but designing project activities should base on the needs of the above objects to ensure organizations implement. In this process, the work of the Center depends on the cooperation of multiple departments, which requires the 
Center to prepare and coordinate for this multi-sectoral action.

In order to achieve the goal of support, the Center should not only pay attention to the present and just focus on the basic activities of propaganda, planning and implementation in daily affairs, but also offer some grounds for decision-making to university teaching and learning reform through a series of investigations and researches. In addition, the premise of promoting teachers' development is to create a good teaching and learning culture, that is, advocating teaching consciousness, and creating an atmosphere of valuing teaching and learning, the Center should be the main advocates and promoters of this goal.

\subsection{Adhere to Principle of Integrity, Strengthen the Organization}

According to the experience of running CTLD at home and abroad, the Center is the core of teaching management in the institutional setting, directly leaded by the vice president or vice president in charge of teaching and learning. The Center directors with the background of pedagogy or the experience of studying in higher education, mostly work in the first line of teaching and research. The director of the Center has to master the strategic objectives of the Center's development and commit to work.

The central staff should adopt a combination way of part-time and full-time, except the general administrative staffs, but also need a number of specialized teachers, shouldering their own duties to serve as consultants or subject teaching experts. In addition, the Center in the teaching process of the co-ordination of teachers, in the multi-subjects, multi-sectors coordination process, must emphasize synergies. Because only by breaking through the barriers between teachers, students, functional departments, departments and working together to play the full of innovative vitality, can university teachers achieve the depth of cooperation in teaching work.

\subsection{Adhere to the Principle of Service, Internal Work Concept}

“Good teachers can make sure qualified education”. Good teacher's connotation appealing to the demands of society, develops constantly. So CTLD providing services should be a kind of developmental service referring to the needs based on studying teachers' and schools' development. This service guiding teachers to carry out conscious teaching behaviors and reflection, can reshape the teacher's self-value in teaching, making whole process a continuous, dynamic and interactive process. Besides, it also is an ideal central work model. In order to better reflect the service principle, some basic work must be done before the implementation of the project, such as establishing teacher's visibility, making university teachers and students and heads of departments and administrative departments understand the Center, then offering them conditions and opportunities to readily accept the center and meeting their needs. In addition, appropriate plans should be made in the pre-, mid- and post-phase of the implementation of the project. 


\subsection{Adhere to the Principle of Differentiation, Establish the Development Direction}

During the visit to Peking University in 2014, General Secretary Xi Jinping pointed out that "running world-class universities in China must have China's characteristics" (Xu \& Huo, 2014). Faced by the social demands for talent diversification and the connotative development of colleges and universities, so to speak, carrying out the featured construction, and seeking a different path has become a key point in the reform of colleges and universities. In this context, what kind of role should the Center play in the development of institutions? The importance of "think tank" construction has been stressed in the Third Plenary Session of the Eighteenth Central Committee of CPC. From this point of view, CTLD serves as "think tank" of the development of institutions in the new era, meaning playing the role of experts in grasping the direction of school reform and making teaching development strategies. In addition, the Center must adjust its development direction and construction accordingly, considering the different positioning and mission. As regards how to learn experience from others and base itself on universities, teaching situation and learning situation, "To establish the characteristics matching CTLD" will be the focus of our next step in the construction of the Center.

\section{What Does CTLD Construct?}

CTLD at home is still in the nascent development stage, the differences of specific social environment determine that we can't copy the foreign construction experience, and must achieve the localization of the central construction. In 2012, the Ministry of Education put forward six functions of the Center in the construction of the National Teacher Development Demonstration Center: teacher training, teaching and consulting, teaching reform, quality assessment, integrated resources and demonstration radiation. These six functions are the main tasks in the development of teachers' teaching and learning in colleges and universities. Combined with the existing practice of the domestic the Center, the six functions can be transformed into three levels of development paths, namely, foundation development, expanding development and characteristic development.

\subsection{Development Contents of the Grass-Roots Basic Level}

The basic work of the Center includes daily affairs, teachers training, "teaching and learning" consulting and research work. To be specific, it works to help new teachers understand the characteristics of students and adapt them to the university teaching and learning environment. Via luncheon, workshops, teaching seminars, expert advice, online learning and other measures, the latest teaching theory knowledge can be obtained to understand the nature and process of learning and finally improve its own teaching methods and techniques. Teachers should be encouraged to carry out teaching researches and experiments, and universities also should provide funds support, reference books, literature research, online resources and expert advice to help teachers to improve the effec- 
tiveness of teaching action researches. By establishing teaching awards in recognition of innovative and outstanding teachers and teachers in the assessment, teachers can be encouraged to devote to teaching work, actively conducting researches and exploring of teaching methods. Teaching feedback and consulting can be obtained by hiring senior skilled teachers and prominent teachers inside and outside the universities and attending lectures or observing teaching videos, and student academic evaluation can be made and implemented through questionnaire surveys.

\subsection{The Development Contents of the Expand Level}

Expanding the development content of the level means preparing for "future education", mainly referring to update the concept of teachers, to enhance the level of education technology. In the context of educational information, the Center needs to regard educational technology as an important medium to promote the effectiveness of teaching. The Center will introduce innovative ideas to teachers, providing opportunities for peers and experts to discuss and applying new technologies to teaching, developing their ability to use educational technology, encouraging and assisting them to produce a variety of teaching courseware and create a digital learning atmosphere.

The Center must provide services including books, brochures, teaching videos, social newsletters, research literature and other resources for teachers to get the latest teaching information and obtain information on improving their teaching. In addition, it should also eliminate the strong technical standards by means of reflection, criticism and practice, and pay attention to the change of teachers' attitudes and behaviors, and then promote the structural development of teachers in knowledge, skills, attitudes and behaviors, and finally complete the core mission of teachers development. Besides, in order to allow graduate students to have opportunities to hone teaching experience, the Center should let graduates serve as teaching assistants in basic disciplines, arranging training courses and study, teaching assistant workshops, face-to-face discussion among senior teaching assistants and other activities to promote university graduate teaching assistant system.

\subsection{The Development Content with Characteristics}

The history of the world education shows that different countries largely differ in the choice of educational development models and education development paths, which thus gradually forms their own characteristics (Qu, 2015). At present, one of the main problems in the development of colleges and universities is that the phenomenon of serious "homogenization" in colleges and universities. Many colleges and universities still put most of their efforts on pursuing "big and complete" professional disciplines, obsolete and identical professions, and modes of talents cultivation inappropriate to actual demands. There are many universities blindly pursuing the number of doctoral degree pilots, the amount of published papers and national issues. As many universities with dis- 
tinctive industry background upgraded or renamed, they gave up traditional advantages of application and skills ( $\mathrm{Du}, 2014)$. The new development situation of colleges and universities urges us to think what universities are, what universities should construct and how to run universities. This further deep reflection is how teachers teach in universities, how students learn. Therefore, setting up the teaching and learning development organizations which fit for its own features promotes the teaching reform in Colleges and Universities that has become an important issue in current work of higher education institutions.

According to the South-Central University for Nationalities' development goals of "building a distinctive high-level national university with distinct characteristics and greater satisfaction with the people", we have formulated a number of methods to promote the development of the Center. For example, promoting the construction of the Center of the national universities as a growth point and the development of teachers' teaching and learning in Universities for Nationalities, by establishing Teachers Teaching and Learning Development Alliances in universities for nationalities, promoting synergistic innovation amid the teaching development of universities for nationalities and encouraging to set up symbiotic mechanism of "Teaching Center-Teaching Culture", three synergistic forces can be integrated among "Governing Bodies-he Universities for Nationalities-the Universities Subject (under the management of teachers and students)".

\section{Conclusion}

At present, the construction of CTLD in China has begun to take shape, but its operation is still relatively loose and the fundamental reasons lie in lacking necessary research and thinking on the role and mission of CTLD. Han Yu (768 $824)$, a very famous poet in Tang Dynasty, put forward in his article Shishuo that "A teacher is a kind of person who could propagate the doctrine, impart professional knowledge and resolve doubts". This is the basic requirement to teachers. From this point of view, the function of CTLD should be "how to propagate the doctrine, impart professional knowledge and resolve doubts". Adding "why" focuses on highlighting the demands of center in the "should be" and "would be" as well as in the promotion of ideas and practice. Of course, this is only the basic goal of college teachers' teaching and learning; its ultimate goal, undoubtedly, still lies in the professionalization of teachers as a carrier to promote the socialization of students and realize students' self-development.

In July, 2016, the Ministry of Education issued the Guiding opinions of the Ministry of Education on deepening the reform of teaching and learning in Colleges and Universities affiliated to central departments, again clearly put forward that universally establishing CTLD is not only an important measure which China takes to consolidate the fundamental position of undergraduate teaching and learning, but also reflects the national expectations for the Center. Thus, supporting the development of Center will be a long-term national policy. Under this background, I maintain that the future research and development of Center 
need to focus on the following issues: how to highlight the service orientation, how to effectively carry on teaching and learning consulting, how to develop six major functions of the Center in order, how to realize the characteristic construction and differentiated development of CTLD. In short, the construction of CTLD needs to fuse Chinese traditional education culture, actively promoting the localization process as soon as possible, and becoming one of the core powers for universities.

\section{Project Funded}

Research Projects of Teaching and Learning Reform of South-Central University for Nationalities: The Origin, Present Situation and Evaluation of Center of Teaching and Learning Development in China University (JXZX2016005).

\section{References}

Cook, C., \& Kaplan, M. (2011). Advancing the Culture of Teaching on Campus: How a Teaching Center Can Make a Difference. Herndon,VA: Stylus Publishing.

Du, Y. B. (2014). Higher Education Should Be Adapted to Developmental Needs of Economic Society. China Education Daily.

Fan, X. J. (2014). System Construction of Young Teachers' Teaching Abilities Cultivation Mechanism. Guangming Daily.

Qu, Z. Y. (2015). From International Perspective, 2014 China Higher Education Hot Issues. China Education.

Sorcinellir, M. D., Austin, A. E., Eddy, P. L., \& Beach, A. L. (2005). Creating the Future of Faculty Development: Learning from the Past, Understanding the Present 1st Edition. Jossey-Bass.

Shanghai Jiao Tong University (2015). Introduction for Center of Teaching and Learning Development.

The Ministry of Education (2016). Guiding Opinions from the Ministry of Education on Deepening the Reform of Education and Teaching in Institutions Affiliated to the Central Departments.

http://www.moe.edu.cn/srcsite/A08/s7056/201607/t20160718_272133.html

Xu, J. Y., \& Huo, X. G. (2014). Xi Jinping at Peking University Stressed that Young People Should Consciously Carry on Core Socialist Values, Work Hard with Motherland and People to Create a Wonderful Life. People's Daily.

Xi, J. P. (2014). Be a Good Teacher for the Party and People. Speech at Symposium with Representatives of Teachers and Students of Beijing Normal University. China News Network. http://www.chinanews.com/gn/2014/09-10/6575002.shtml

Xi, J. P. (2015). Shoulder Responsibilities and Mission. Warmly Congratulate the 31st Teacher's Day. China Education News. 
Submit or recommend next manuscript to SCIRP and we will provide best service for you:

Accepting pre-submission inquiries through Email, Facebook, LinkedIn, Twitter, etc. A wide selection of journals (inclusive of 9 subjects, more than 200 journals)

Providing 24-hour high-quality service

User-friendly online submission system

Fair and swift peer-review system

Efficient typesetting and proofreading procedure

Display of the result of downloads and visits, as well as the number of cited articles Maximum dissemination of your research work

Submit your manuscript at: http://papersubmission.scirp.org/

Or contact ce@scirp.org 